\title{
The Interactive Whiteboard and Educational Software as an Addition to the Teaching Process
}

\author{
Marjana BARBARIĆ PARDANJAC, Dijana KARUOVIĆ, Erika ELEVEN
}

\begin{abstract}
This paper deals with the possibilities and effects of the interactive whiteboards and use of educational software as a contribution to teaching process. The interactive whiteboard with its own characteristics allows viewing of photo and video formats, use of educational software, document editing by using different software applications and so on. In this paper, emphasis is given to the use of educational software through interactive whiteboard and the analysis of their impact on teaching process improvement. Besides, from the fact that students learn new content in a more entertaining and approachable way, teachers at the same time improve the level of their professional development. The research in this paper includes both empirical and theoretical character, conducted by surveying a representative sample. It should provide answers about the impact and effects of interactive whiteboards and educational software on increase of the quality of teaching and the success and motivation of students in relation to the teaching realized in a traditional way.
\end{abstract}

Keywords: education; educational software; interactive whiteboard; teaching process; user's motivation

\section{INTRODUCTION}

Education is an organized process of transferring knowledge, skills, values and beliefs and is prerequisite for any improvement at individual or social level [1]. Due to technological advance, new opportunities have emerged to fulfil the process of education. Amongst them, the strongest representative is the computer, which with its own abilities adds a completely new dimension to the education process $[2,3,4]$. Education now aims to provide not only pure knowledge, but also continuous learning, critical thinking, questioning, as well as to keep up with innovations. Flexible training modalities and the use of self-learning methodologies as well as advanced technological support can provide adequate interactive learning [5].

Technology in today's society is rapidly evolving, influencing many aspects of our social and professional lives [6]. It is known that Informal education facilities create active environments for students to interact with one another and engage them in discussion, while at the same time they are analysing aspects of the scientific method [7].

Interactive whiteboard (further IWB) systems comprise a computer linked to a data projector and a large touch-sensitive board displaying the projected image; they allow direct input via finger or pen so that objects can be easily moved around the board ('drag and drop') or transformed by teacher or students.

IWB offers a wide range of potential benefits for the presentation of the material in terms of the relative ease of integration of a large number of presentations and ICT, which, together, provide new opportunities for strengthening pedagogical strategies [8]. Interactivity between teachers, pupils and IWB provides the focus for the analysis of learning and teaching in the context of this non-standard learning environment [9]. The positive effects of IWB are pointed in [10], as it allows easy and effective incorporation of a wide range of multimedia sources into lessons (text, images, video, sound, graphs, websites). The research [11] shows that students are convinced that teaching with the IWB has positive effect on their learning, especially because of the visualization and contextualization, effectiveness of presentations and motivational factors. In a study [12] authors observed how IWB affects the students learning effectiveness and their perception towards learning environment. The results indicated that students from the IWB group learn more effectively and with more positive attitudes than traditional group. The papers $[13,14]$ indicated the advantage of using IWB for quickening the pace of lessons using pre-stored materials, which reduce the need for writing on the board. Due to the ease of use, even those teachers who avoid the use of ICT can accept IWB as a teaching tool [15]. In study [16] authors think that it would be wrong not to use IWB in schools since the results of their study showed a positive effect of using IWB in classes.

After this section of the paper, which represented an Introduction, and brief overview of related papers from the given field, emphasis will be given to the effects of the application of interactive whiteboards and educational software in the teaching process in primary schools.

\section{INTERACTIVE DEVICE AND SOFTWARE 2.1 Interactive Devices}

In the growing supply of IWBs on the market today, two commercial solutions can be found. The first solution is a classic IWB, the standard one with fixed dimensions, with the elements which resemble the classic whiteboard (electronic chalk and e-sponge), with an area that is sensitive to the touch and is connected through a standard USB into computer. While the second solution is based on monitoring the position of electronic pen with a device which is usually placed on the side, pointed to the desktop, connected to a computer via USB or Bluetooth. In both cases, computer and video projector, that will project image from computer to the interactive surface, are needed as the basis of hardware. Both solutions have their advantages and disadvantages - the first one has a big advantage of "natural ability" environment, the system is easy to use, training is fast, but the size of the table is restricted by the size of hardware i.e. in an area that is 
sensitive to the touch, the system is static, so it cannot be transferred from one room to another, and the price is unacceptable to most institutions that have a need for this presentation asset. The advantages of the other solution lie primarily in the mobility of the whole system, size of the "table", i.e. virtual surface has no limitations, and the price is 4-5 times lower, while the disadvantages are: the need for more training of working with the pen, inaccuracies of the system and the less powerful support.

During $2006^{\text {th }}$ the Japanese company known for production of home consoles Nintendo, has released a new device called the Wii to the market. Most interesting at this device was the controller (the Wii Remote Wiimote), which brought to the players a new dimension of a game play. With the help of an accelerator and an infrared detection, the players get ability to control the game with their physical movements, not only by pressing the buttons.

While television and film have impact only on the audiovisual skills of the users, the computer is capable of activating the senses of sight, hearing and touch of the users. IWB has the capacity to provide a higher interactive potential for users, and development of their individual, intellectual and creative abilities $[17,18]$.

\subsection{Interactive Software}

The two kinds of commercial software for Windows OS which extends capabilities of mentioned system (bringing it closer to the classic IWBs and their abilities) will be described. These programs, besides options for mouse control, simulation of the left/right button, have an option of highlighting any image that appears on the screen, adding new features to them. The basic power of HCI approach of designing users' interface is contact with users. Because of that, a special attention should be paid to the specific characteristics of users $[19,20,21]$.

Depending on the system type designed, the focus is put on different characteristics of the users. It is impossible to satisfy all the users so the target group is defined and attention is put on the typical representatives of the group.

Relevant factors at categorization of the users' target group [22]:

- the time for studying - how much time a typical member of the group needs in order to learn how to use commands relevant for the task

- performance - how much time a typical member of the group needs in order to solve the problem (including mistakes and correction)

- mistakes - what type of mistakes/errors a typical user makes and how often he/she makes them during solving the problem (error handling)

- the time necessary for repetition - how a typical group member maintains his/her knowledge

- $\quad$ satisfaction - how much a typical group member likes different aspects of the software (interviews, surveys of users, etc.)

Important characteristics of the users (considering a target group) are: education level, psycho-physical abilities, age, cultural and ethnical heritage/ genetics, motivation, gender.
Besides the regular users there are users with special needs, who represent a special category. The interactive software designed for them is characterized by the following features: for users with vision impairments - by increasing the display surface's size or by converting the entrance/exit (input/output) into Braille alphabet or voice; for users with hearing impairments - by converting audio information into video presentation; for users with motoric disorders - through the use of special input/output devices such as special keyboards, joysticks, keys, a "head-mounted" optical mouse etc.

It should not be forgotten that every application has several classes of users; therefore, different levels of interaction should be anticipated. Due to the user's ability to improve themselves, some individuals will probably go from lower to higher levels of interaction during software usage.

While designing software there are two main factors that should be taken care of [23]: usability (it is relied on function, effective presentation of information and product), and aesthetic side (by using appropriate colours, shapes, graphics, etc.).

Targeted users also represent one of the main factors that should be taken care of.

A good design should attract the attention of as many users as possible so it has to be original, beautiful, but it also should reflect the very essence of its purpose. Design makes the first impression and because of that it is necessary for it to be of high quality. Based on the defined objectives and tasks that software must achieve, criteria for its development are defined and need to be respected.

One of the basic requirements is to achieve the highest possible level of software interactivity, because it is impossible to imagine educational software without this. Therefore, there must be a high level of interaction between user and software itself, primarily through the possibility of user's ability to choose the path of knowledge acquisition. Thus, software individualization is enabled, i.e. software customization to personal requirements is provided.

Iwiiboard - is a custom software program that integrates everything needed for one to work with the wiimote device as an IWB (Fig. 1). In addition to finding and connecting with hardware easily, it also has the following characteristics: a pen for freehand writing on the screen; a right click function that simulates the right button of a mouse; a blackboard for writing on a monochrome surface; a snapshot for capturing screen content; miscellaneous tools for system applications' quick start, and a screen keyboard for writing on a virtual keyboard.

Under the pen option, a user can find many new options, and some of the most interesting are: highlighter transparent highlighter bookmark; size - the size of a pencil; rubber - eraser; shapes - drawing of defined symmetrical shapes; zoom - pounding parts of the screen enlarger.

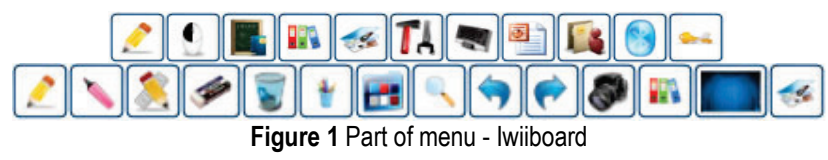


Smoothboard2 - unlike Iwiiboard, this software (Fig. 2) has fewer options, but it is much more optimized, primarily in explanations of current display on computer screen. What set it apart are completely defined tools that help working with PowerPoint, as well as setting options in user interface.

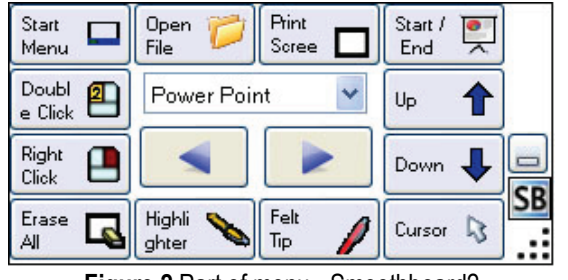

Figure 2 Part of menu - Smoothboard2

Adresia, Classroom Presenter, E-pointer, Linktivity Presenter, Massive board, Pointofix, Screen Marker, Zoomit are just some of many free programs for displaying and drawing on the screen, but are less used than the two previously mentioned.

\section{EDUCATIONAL SOFTWARE}

Educational software, or computer applications developed for the purpose of teaching and learning, arrived with virtually the first desktop computers. Therefore, educational software is any type of software used for educational purpose or matter.

Users accept and process information provided by educational software in various ways, so it is necessary to know types of user personalities while creating it, [24] visual type - likes to see information; audible type - likes to hear information; kinetic type - likes to acquire knowledge through independent work.

The purpose of the software is not to provide an individual assessment of a student's progression, but rather to create new atmosphere in the classes by the use of modern teaching aids such as IWB.

Besides that, educational software with "smartboards" can be used for other purposes, such as practice exercises and tests. The aim of the practice is to improve users' interaction with the software. For example, to solve the task it is necessary to recognize and redraw some elements from one part to another part of the screen, and while the standard test includes questions and answers with multiple choices, software checks the user and shows the number of correct answers.

\subsection{The Example of Educational Software}

Students of Information Engineering department at Technical Faculty "Mihajlo Pupin" in Zrenjanin, at Computer-Human Interaction course, under the supervision of the authors, created several versions of educational software. This software is mostly created by the usage of program tools, such as Microsoft Visual Studio or Adobe Director. All the elements necessary to complete good interactive teaching are integrated using its advanced technologies (Fig. 3).

In addition to options that interactive software system offers for navigations through presentation (Smoothboard2 was chosen for its optimization), options that display explanations over existing images are also used. During the collection of multimedia materials, attention was given that images were - on one hand presented with a lot of colours and visible details, and on the other side, that each image (chart, table) had an option for simple processing that can be performed on the IWB during lectures. For example, the omission of arrows that connects elements or framed picture parts allows the use of the electronic pen during a presentation for drawing "missing" elements (see Fig. 4a and Fig. 4b).

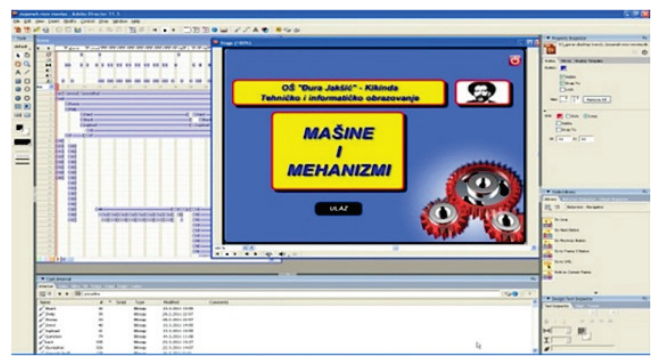

Figure 3 The working screen of interactive educational software
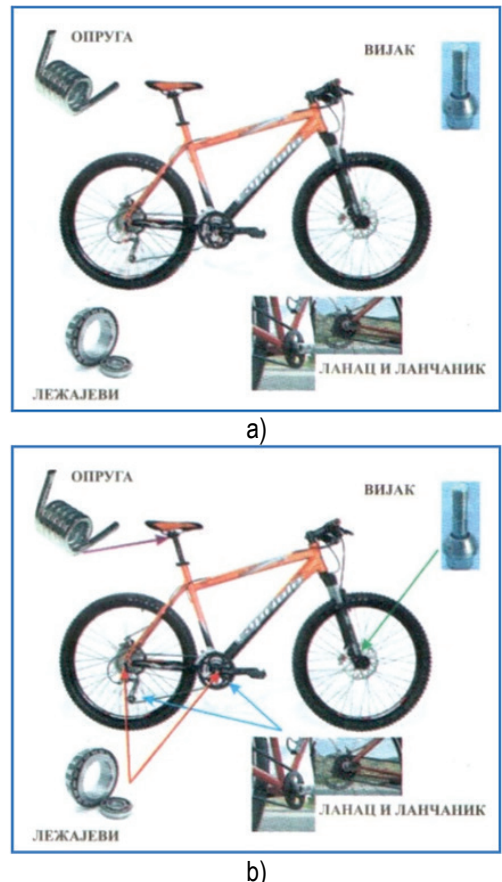

Figure 4 a) Example of image used in the interactive presentation; b) Marked with arrows through "smart" whiteboard

Software that is presented below shows the teaching unit Machines and mechanisms, which is a part of the Technical and Informatics course for seventh grade (Fig. 3). After initial screen, which shows the title and a short introductory animation, main menu screen which is divided into seven groups is displayed: Introduction; Principles of work; Elements; Production machinery; Transportation machines; Exercises; Tests.

At the bottom of the screen, there are navigation keys that remain present throughout the entire presentation without changing form or place (options next, return and menu above). At the upper part of the screen, there are keys for exiting the program, seeking help, and returning to the main menu. Each teaching unit is presented with many pictures and some videos. 
Practices and tests are planned for students. For example, one exercise consists of identifying tools which work on the principle of the lever or wedge. At the bottom of the window there were following tools: hammer, knife, pliers, hatchet, saw, can opener, door handle. The task was to allocate these tools to the appropriate groups with help of electronic pen, i.e. images of elements should be dragged to the appropriate rectangles named: "The principle of leverage" or "The principle of the wedge." When all the elements are arranged correctly, the program will confirm the accuracy of finished task. See Fig. 5a and Fig. 5b.
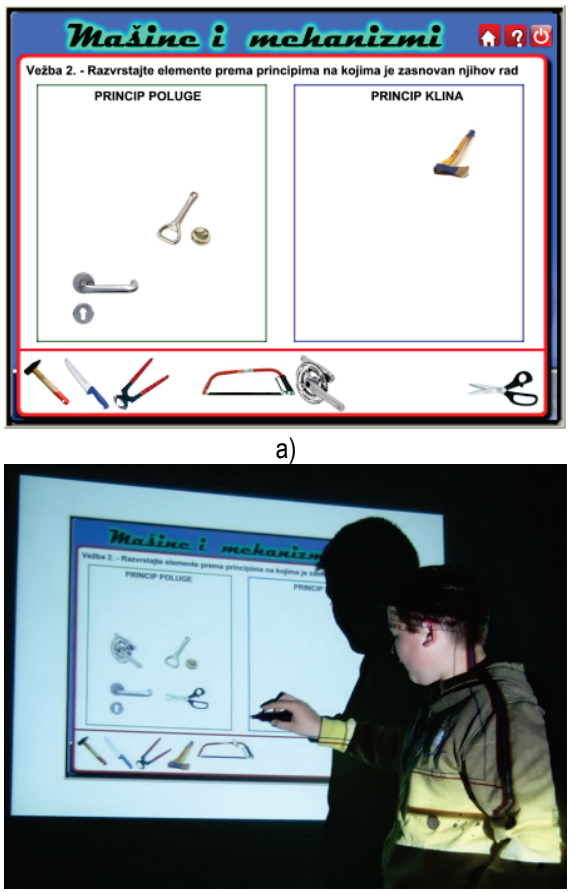

b)

Figure 5 a) Example of exercise recognition principles; b) Exercise in class recognizing the principle of work.

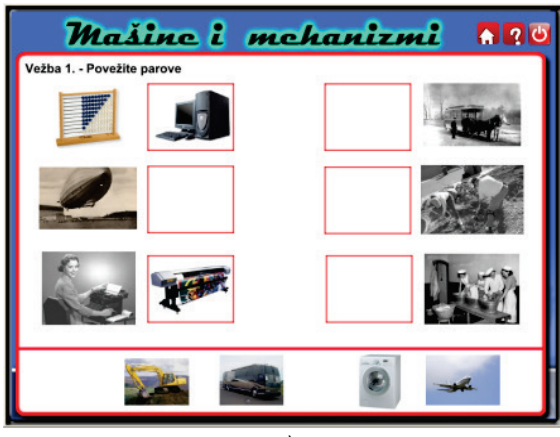

a)

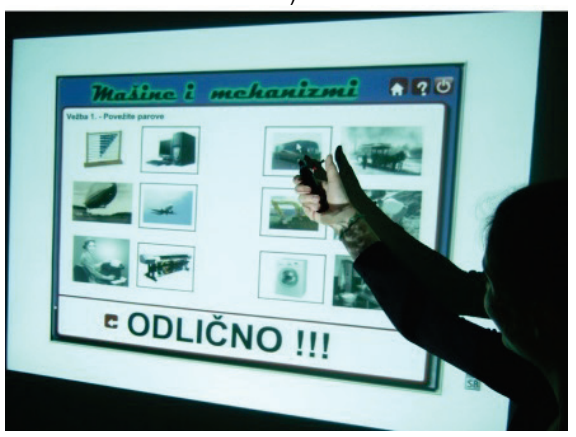

b)

Figure 6 a) Example of exercise connecting pairs; b) Exercise in class connecting pairs.
Another example of the practices was to "connect couples". Couples were formed from images of some old appliances or hand tools on one hand and modern machinery on the other (for example: balloon $\rightarrow$ plane, harness $\rightarrow$ bus, abacus $\rightarrow$ computer, shovel $\rightarrow$ digger, etc.). See Fig. 6a and Fig. 6b. Students' activity is expected here and it is important that everyone is active in using electronic pen on the whiteboard.

Knowledge test was a set of twenty questions with multiple choices. In the right part of screen, the appropriate software script should have current number of points entered. Tests should be repeated, until whole group of students do the test with the maximum number of points, and improve their knowledge.

\section{METHOD \\ 4.1 Problem Definition}

Education has a leading role in acquisition of basic knowledge, which allows each individual to be able to live and work in modern social environment. In Serbia, basic educational system includes one year of mandatory preschool period followed by eight years of elementary school. According to the equipment and technical support, some preschools have started to use educational software in teaching process. The interaction between child and the computer is of great importance for obtaining IT skills. Informational knowledge acquired through that period, improves during further education and lasts for life.

Use of the most modern teaching equipment always brings results. Although the use of IWBs appears shyly in schools in Serbia, it will, almost certainly, attract attention of young people who are always ready to use multimedia in the ways previously unknown to them.

Use of interactive whiteboards and multimedia application allows teachers to present material in a better and more interesting way.

Statistic shows that up to three years ago, the number of installed IWBs in the world stood at 750000 and that at the end of the second decade of the $21^{\text {st }}$ century it shall be over one million.

The research problem that this paper addresses is whether it is justified to use interactive devices in educational process, and whether it is necessary to aim at the procurement of these devices in order to modernize schools, and whether their use can influence teaching improvement.

\subsection{The Research Goals}

The aim of the research is twofold. The first aim is to determine facts about users regarding the acceptance of information from the standpoint of content and about trends of development of user interface as part of the educational software. The second aim is to find under what conditions and for what reasons and motives educational software has a significant impact on the quality, efficiency and productivity of the educational process.

\subsection{The Research Hypothesis}

General hypothesis of research is that educational software and IWB provide greater direct knowledge for 
users, as well as a higher level of cognitive, affective and sensor - motor skills, compared to traditional teaching.

The first sub-hypothesis: computer literacy is important for work with educational software and IWB.

The second sub-hypothesis: use of educational software and IWBs for educational purposes increases students' motivation to learn.

\subsection{Method of Research}

The method of parallel groups was applied for this research. This technique makes it possible to compare results between the two groups (control and experimental). Groups are equal in number; computer literacy, age and gender. Computer literacy was determined by testing the ability to work with a computer before the experiment. Marks from the last control exam were adopted as previously acquired knowledge. Questionnaires and tests were used as research instruments. Furthermore, an analysis of documentation, observations and testing and analysis of the results were applied.

\subsection{Sample and Organization of the Research}

The targeted population is about 1200 . With the $95 \%$ level of confidence, and the interval of confidence of $\pm 5 \%$, the targeted sample size should be 291 participants, so 298 participants of this study fulfil required conditions. The study sample consisted of seventh grade students from several primary schools from Vojvodina, which were surveyed during 2012-2014 period. The students were divided into two groups: control and experimental group. Selection criteria for schools were the existence of IWB, which was necessary for carrying out the experiment.

After group forming, experimental procedure was approached. After the experiment, students were doing a test to determine whether and which group mastered provided material in a better way. Students of experimental group also were doing a survey to determine attitudes and opinions about work with an IWB and educational software.

\section{RESEARCH}

\subsection{Initial Data and Group Forming}

The study sample consisted of primary schools students, with marks from the latest control test, which were taken as a measure of their knowledge, instead of initial test (Tab. 1).

Based on the data from Tab. 1, the students were divided into two homogeneous groups - Tab. 2 .

Score according to marks from the control task is shown in Tab. 3.

Table 1 Research sample - initial data

\begin{tabular}{|c|c|c|c|c|c|c|c|c|c|}
\hline \multirow{2}{*}{ Number of students } & \multirow{2}{*}{ Male (M) } & \multirow{2}{*}{ Female $(\mathrm{F})$} & \multicolumn{5}{|c|}{ Mark } & \multirow{2}{*}{ Average } & \multirow{2}{*}{ St. dev. } \\
\hline & & & 1 & 2 & 3 & 4 & 5 & & \\
\hline 298 & 162 & 136 & 16 & 42 & 78 & 82 & 80 & 3,55 & 1,20 \\
\hline
\end{tabular}

Table 2 Students division in control and experimental group

\begin{tabular}{|l|c|c|c|c|c|}
\hline & Sample & Male (M) & Female (F) & Average & Med. \\
\hline Control group (CG) & 150 & 80 & 70 & 3,56 & 4 \\
\hline Experimental group (EG) & 148 & 82 & 66 & 3,57 & 1,18 \\
\hline
\end{tabular}

Table 3 Score according to marks from the control task

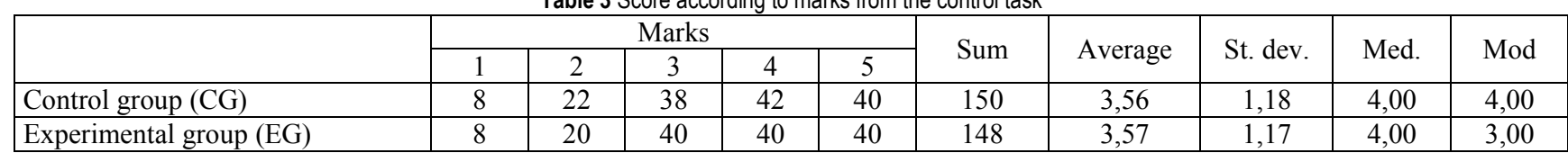

\subsection{Execution of the Experiment}

To control group students teaching materials were shown in a traditional way using frontal teaching. Opposite to them, experimental group students had teaching material presented in a computer laboratory in which an IWB with the educational software "Mechanics and Mechanisms" had been installed. Before processing the material, experimental group students were familiarized with the use of the IWB. After the teacher had presented lesson, students were learning presented material through independent work - doing exercises that the educational software offered. Upon the completion of this period, during second class, the students of both groups were tested to determine whether one group mastered the teaching content better (Tab. 4).

Also, according to degree of computer literacy, experimental group students were divided in two subgroups, before experiment beginning. The aim was to determine, based on the test results, whether and to what extent this affects work with educational software, as well as IWB.

Table 4 Score according to marks from the final test

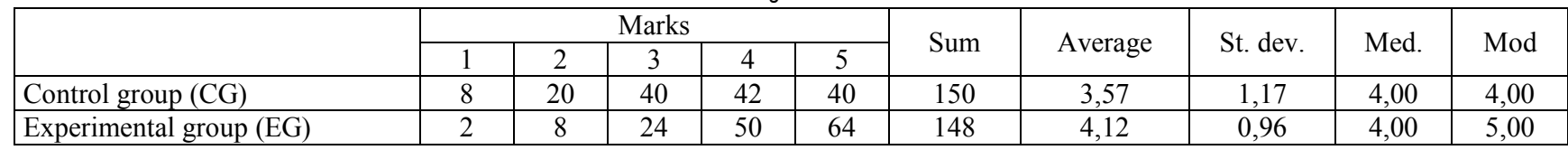




\subsection{Test Results}

After the experiment, the test was conducted and results are shown in Tab. 4.

Before the start of the experiment (Tab. 3) both groups had nearly identical average of 3,56 for control group (CG) and 3,57 for experimental group (EG), and considering that standard deviation value was approximate, it can be concluded that students were properly arranged in groups.

The test results (Tab. 4) - as it was expected - showed that the control group maintained the average that was prior to experiment, because material had been presented to them in the same way as during the whole school year. Experimental group members increased their average by $11,0 \%$ compared to the maximum mark (Fig. 7), which can be interpreted as contribution of educational software and IWB implementation to improvement of teaching process, because teaching material was shown to students in a new and more interesting way.

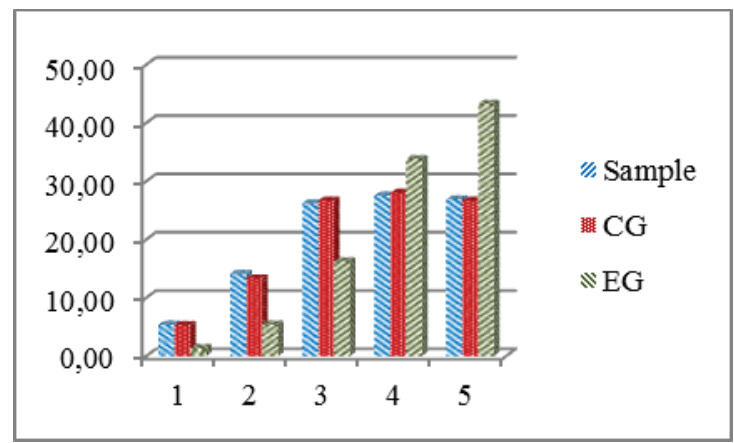

Figure 7 Comparative display of initial and final results for whole sample and both groups
After examining the results of the test, it can be seen that there has been an increase of mode value, so it can be concluded that with implementation of educational software and IWBs, learning material becomes clearer, more understandable and accessible, and all of that affects students' better results (Fig. 8).

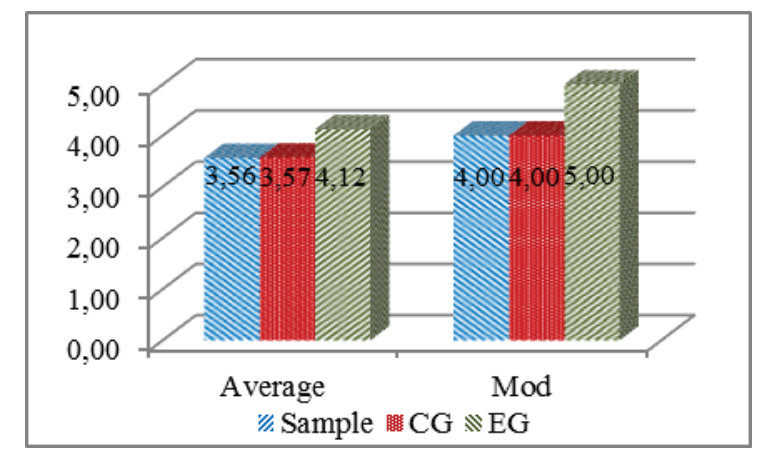

Figure 8 Comparative displays of average values for sample and both groups

\subsection{The Formation of Subgroups and their Results}

For the purpose of further research, EG is divided into two subgroups, depending on the level of students' computer literacy, which is determined by survey. EG1 group consisted of students with lower and EG2 of students with higher computer literacy. Results for these two subgroups are obtained both from the initial data collection and final test, and can be seen in Tab. 5 .

All students had classes in a traditional way before experiment, which did not require computer literacy for learning, so average grades of both experimental groups were approximate.

Table 5 Score according to marks from the test for Experimental group

\begin{tabular}{|c|c|c|c|c|c|c|c|c|c|}
\hline & \multicolumn{5}{|c|}{ Marks } & \multirow{2}{*}{ Sum } & \multirow{2}{*}{ Average } & \multirow{2}{*}{ St. dev. } & \\
\hline & 1 & 2 & 3 & 4 & 5 & & & & \\
\hline \multirow{2}{*}{ Initial data collection } & 4 & 8 & 20 & 14 & 16 & 62 & 3,48 & 1,19 & EG1 \\
\hline & 4 & 12 & 20 & 26 & 24 & 86 & 3,63 & 1,16 & EG2 \\
\hline \multirow{2}{*}{ Data from final test } & 2 & 6 & 14 & 18 & 22 & 62 & 3,84 & 1,11 & EG1 \\
\hline & 0 & 2 & 10 & 32 & 42 & 86 & 4,26 & 0,77 & EG2 \\
\hline
\end{tabular}

However, although both subgroups progressed after the experiment (teaching through educational software and IWBs), it can be noted that the subgroup with higher computer literacy (EG2) achieved greater progress $12,6 \%$ compared to the maximum grade, as opposed to $7,2 \%$ for subgroup EG1.

\subsection{Survey about Interactive Whiteboard and Educational Software Use}

Given that the application of educational software with the help of IWB is a novelty for Serbian educational system, further surveys were carried out to determine students' attitudes and opinions about their use in the teaching process. This survey was conducted only with the students of experimental group, after the experiment. The questionnaire consisted of statements with the responses in the form of Likert Scale. The respondent answers were shown by the level of their agreement or disagreement with the content of the statements (Tab. 6). The values were as follows: $\mathrm{A}=\mathrm{I}$ absolutely agree, $\mathrm{B}=\mathrm{I}$ agree, $\mathrm{C}=$ No opinion, $\mathrm{D}=\mathrm{I}$ disagree, $\mathrm{E}=\mathrm{I}$ absolutely disagree.

Table 6 Survey about interactive whiteboard and software use

\begin{tabular}{|c|c|c|c|c|c|c|}
\hline & \multirow{2}{*}{ Statement } & \multicolumn{5}{|c|}{ Answers \% } \\
\hline & & A & B & $\mathrm{C}$ & $\mathrm{D}$ & $\mathrm{E}$ \\
\hline $\mathrm{S} 1$ & The learning material is shown in a more interesting way & 36 & 33 & 12 & 10 & 9 \\
\hline $\mathrm{S} 2$ & I would like educational software and IWBs included in teaching process & 43 & 29 & 10 & 7 & 11 \\
\hline S3 & Learning with IWB is more interesting than traditional learning & 46 & 15 & 11 & 13 & 15 \\
\hline S4 & Less time is needed for understanding material than in classical class & 57 & 16 & 11 & 5 & 11 \\
\hline S5 & It is easier to learn because there are more examples offered & 42 & 23 & 11 & 14 & 10 \\
\hline
\end{tabular}


Students felt that the teaching supplemented by educational software and IWBs offered learning in a new and interesting way (S1). In fact, as much as $72 \%$ of students stated that they would like to take classes realized in this way (S2). Also, they said that this type of teaching was both more interesting than classical education (S3 - 61\%) and more efficient because they needed less time to master the material (S4-73\%). It was of particular significance to them that educational software offered a lot more practice and examples (65\%) than a teacher can perform in traditional classes (S5).

\section{DISCUSSION AND CONCLUSION}

\subsection{Discussion}

Based on the results it can be concluded that there is ability and interest of students to apply educational software and IWBs, because this way of learning improves quality of teaching making it visual and interactive. The research presented in this paper confirmed and verified the fact that success of today's educational process is widely influenced by the use of computers and interactive devices such as IWBs and educational software.

The results obtained in this study show that educational software provides greater direct knowledge of users, as well as a higher level of cognitive, affective and sensor - motor skills, compared to traditional teaching which proves the main hypothesis.

Although the software presented can be used in a relatively simple and familiar way, for cognition and acquiring knowledge, independent work with the IWB requires a certain computer literacy on the part of students. Therefore, the results of the research showed that the possession of computer literacy is important for work with educational software and interactive whiteboards - a finding that complies with the first subhypothesis.

Interactive whiteboards with appropriate software usage give advantage to knowledge acquisition over classical education. Besides properly presented materials, great impact on work performance success, along with the use of educational software and IWB, has user motivation. The fact that experimental group students better remembered presented material suggests that they were more motivated to work, compared to students in control group, so it can be concluded that the use of educational IWB for education significantly increases the motivation of students' learning, providing evidence for second sub-hypotheses.

\subsection{Conclusion}

The aim of this paper was to determine the facts about the ways of using IWBs and development of user interface as part of the educational software, as well as the motives and conditions that contribute to the fact that the use of educational software has a significant impact on the quality, efficiency and productivity of the educational process.

The authors found that the results of research conducted in this paper, are comparable to similar experiences of international practice. Based on the results it was found that the most significant effects of the application of IWB and software are:

- $\quad$ it allows easier and more effective incorporation of a wide range of multimedia sources into lessons;

- in this way students learn more easily because of the more effective presentation of material and higher level of motivation;

- teachers who initially avoid the use of ICT, accept more gladly IWB as a teaching tool

- teachers can pass through the material more quickly because the use of pre-stored materials reduces the need for writing on the classic board.

One of the noticed differences in comparison with the practice in the world is a lower level of existence of IWB in schools, primarily due to reduced economic power. Another problem that appears in Serbia is the lack of both well-trained teachers and experts who create educational software, poor technical support for the use of such devices as well as shortage of educational software.

It can be concluded that students show ability to learn through educational software and IWBs, and that ability may be influenced by the creation of adequate school habits at previous education levels. One of the essential conditions that learning process through IWBs could be effective is that students possess computer literacy, motivation and readiness for such a type of learning.

In addition to the student's motivation, properly designed educational software has a significant role that will guide students through the process of acquiring knowledge, ensuring an accurate assessment of what has to be learned and providing the ability to understand presented educational material.

Similar to [25], the research has shown that interactive whiteboards are able to keep students involved and foster their attention in every aspect of the curriculum, much easier than without it.

Therefore, the authors are of the opinion that administration needs to invest in equipping schools with interactive whiteboards and necessary software. The invested funds would be returned through a higher level of knowledge, which is the primary objective of each level of education. Based on the experiences related to other ICT equipment, it can be expected that the prices of IWB will be declining in the future, which would make them more accessible. Because of that, there is no doubt that such or similar devices are going to be standard teaching means in almost every classroom in the near future. This paper speaks in favour of supporting and encouraging this trend.

\section{REFERENCES}

[1] Koçyiğit, S. (2014). Preschool Age Children's Views about Primary School. Educational Sciences: Theory \& Practice, 14(5), 1870-1874. https://doi.org/10.12738/estp.2014.5.2393

[2] Minovic, M., Stavljanin, V., Milovanovic, M. \& Starcevic, D. (2010). User-centered Design of m-Learning System: Moodle on the Go. Journal of Computing Science and Engineering, 4(1), 80-95. https://doi.org/10.5626/JCSE.2010.4.1.080

[1] Zheng, B., Warschauer, M., Hwang, J. K. \& Collins, P. (2014). Laptop Use, Interactive Science Software, and 
Science Learning Among At-Risk Students. Journal of Science Education and Technology, 23(4), 591-603. https://doi.org/10.1007/s10956-014-9489-5

[2] Şahin, İ. Ö. \& Kabakçi, Y. I. (2014). Investigation of Prospective Teachers' Information and Communication Technology Integration Practices in Terms of Transformative Learning Theory. Educational Sciences: Theory \& Practice, 14(6), 2293-2303.

[3] Pando Cerra, P., González, J. M. S., Busto Parra B., Rodríguez Ortiz, D. \& Álvarez Peñín, P. I. (2013). Can Interactive Web-based CAD Tools Improve the Learning of Engineering Drawing? A Case Study. Journal of Science Education and Technology, 23(3), 398-411. https://doi.org/10.1007/s10956-013-9471-7

[4] Norris, C., Sullivan T., Poirot, J. \& Soloway, E. (2003). No access, no use, no impact: Snapshot surveys of educational technology in K-12. Journal of Research on Technology in Education, 36(1), 15-27. https://doi.org/10.1080/15391523.2003.10782400

[5] Carrie, J. B., Chandrani, M., Kristy, L. H. \& Aimee K. T. (2014). Getting Students Outside: Using Technology as a Way to Stimulate Engagement. Journal of Science Education and Technology, 23(6), 815-826. https://doi.org/10.1007/s10956-014-9514-8

[6] Gillen, J., Littleton, K., Twiner, A., Kleine Staarman, J. \& Mercer, N. (2008). Using the interactive whiteboard to resource continuity and support multimodal teaching in a primary science classroom. Journal of Computer Assisted Learning, 24(4), 348-358. https://doi.org/10.1111/j.1365-2729.2007.00269.x

[7] Haldane, M. (2007). Interactivity and the digital whiteboard: Weaving the fabric of learning. Learning, Media and Technology, 32(3), 257-270. https://doi.org/10.1080/17439880701511107

[8] Levy, P. (2002). Interactive Whiteboards in learning and teaching in two Sheffield schools: A development study. Sheffield Excellence in Cities Partnership.

[9] Şad, S. N. \& Özhan, U. (2012). Honeymoon with IWBs: A qualitative insight in primary students' views on instruction with interactive whiteboard. Computers and Education, 59(4), 1184-1191. https://doi.org/10.1016/j.compedu.2012.05.010

[10] Yang, K. T., Wang, T.-H. \& Kao, Y.-C. (2012). How an interactive whiteboard impacts a traditional classroom. Education as Change, 16(2), 313-332. https://doi.org/10.1080/16823206.2012.745759

[11] Ball, B. (2003). Teaching and learning mathematics with an interactive whiteboard. Micromath, 19(1), 4-7.

[12] Miller, D. (2003). Developing interactive whiteboard activity. Micromath, 19(3), 33-35.

[13] Kemeny, H. (2005). Transforming Learning? Interactive whiteboards in the primary classroom: case studies from a London school. Proceedings of the Redesigning pedagogy: research, policy, practice conference, Singapore, May June 2005, CRPP Conference Papers.

[14] Amiri, R. \& Sharifi, M. (2014). The Influence of Using Interactive Whiteboard on Writings of EFL Students Regarding Adverbs. Procedia Social and Behavioral Sciences, 98(6), 242-250. https://doi.org/10.1016/j.sbspro.2014.03.413

[15] Aduwa-Ogiegbaen, S. E. \& Iyamu, E. O. S. (2005). Using Information and Communication Technology in Secondary Schools in Nigeria: Problems and Prospects. Educational Technology \& Society, 8(1), 104-112.

[16] D Lee, J. C. \& Hudson, S. (2008). Foldable Interactive Displays. ACM Symposium on User Interface Software and Technology. Proceedings of the ACM Symposium on User Interface Software and Technology / Monterey, CA, 287290. https://doi.org/10.1145/1449715.1449763
[17] Hewett, T. (1996). Curricula for Human-Computer Interaction, The Association for Computing Machinery, New York.

[18] Hourcade, J. P. (2003). User Interface Technologies and Guidelines to Support Children's Creativity, Collaboration, and Learning. University of Maryland. $\mathrm{ftp}: / / \mathrm{ftp} . c s . u m d . e d u / p u b / h c i l / R e p o r t s-A b s t r a c t s-$ Bibliography/2003-21html/2003-21.htm (05.10.2015)

[19] Shneiderman, B. \& Plaisant, C. (2006). Designing the User Interface, University of Maryland, College Park

[20] Brinck, T., Darren, G. \& Scott, W. D. (2002). Usability for the Web. Elsevier Inc. http://www.sciencedirect.com/ science/article/pii/B978155860658650002X (07.11.2015)

[21] Navarro, Ann. (2001). Effective Web Design, Second edition / Alameda, Sybex Inc. 182-198.

[22] Karuovic, D. \& Radosav, D. (2010). Human Computer Interaction Model in Educational Software. Technics Technologies Education Management, 5(1), 198-204.

[23] Drigas, A. \& Papanastasiou, G. P. (2014). Interactive White Boards in Preschool and Primary Education. International Journal of Online Engineering, 10(4), 46-51. https://doi.org/10.3991/ijoe.v10i4.3754

\section{Contact information}

Marjana BARBARIĆ PARDANJAC, PhD

University of Novi Sad, Technical Faculty "Mihajlo Pupin", Đure Đakovića bb, 23000 Zrenjanin, Republic of Serbia

E-mail: marjana.pardanjac@tfzr.rs

\section{Dijana KARUOVIĆ, PhD}

University of Novi Sad, Technical Faculty "Mihajlo Pupin", Đure Đakovića bb, 23000 Zrenjanin, Republic of Serbia

E-mail: dijanakaruovic@gmail.com

\section{Erika ELEVEN, MSc}

University of Novi Sad, Technical Faculty "Mihajlo Pupin", Đure Đakovića bb, 23000 Zrenjanin, Republic of Serbia

E-mail: eleven.erika74@gmail.com 